\title{
Modeling and Simulation of Grid Connected Permanent Magnet Generator (PMG)-based Small Wind Energy Conversion Systems
}

\author{
Md. Arifujjaman* \\ Department of Electrical and Computer Engineering, University of New Brunswick, Fredericton, NB, Canada E3B 5A3, \\ Canada
}

\begin{abstract}
A small scale wind energy conversion system has tremendous diversity of use and operating conditions, and consequently is evolving rapidly along with the large scale wind energy conversion system for generation of electricity in either stand-alone or grid connected applications. In recent years, the grid connected small wind turbine industry is primarily dominated by the Permanent Magnet Generator (PMG) machines. The power conditioning systems for grid connection of the PMG-based system requires a rectifier, boost converter and a grid-tie inverter. Such system should be based on an appropriate control strategy to control the aerodynamic power during high wind speed, maximum power production, and maximum power flow to the grid at all operating conditions. This paper presents mathematical modeling and control strategy for the grid connected PMG-based small wind turbine systems. Furling control and expected dynamics are adopted with the wind turbine for aerodynamic power control, while the optimum speed of the PMG is followed to ensure maximum power production. A novel controller is derived from the optimum speed information that promise maximum power flow to the grid by controlling the boost converter output voltage and current through the duty cycle. It is found that the proposed modeling and control strategy is feasible and results are verified through simulation.
\end{abstract}

Keywords: Furling control, maximum power point controller, maximum power flow controller, permanent magnet generator, wind energy conversion system.

\section{INTRODUCTION}

Wind power is presently considered an optimal renewable technology since it provides a continuously growing contribution to climate change goals, energy diversity and security. Reliable control strategies, custom designed generators, low maintenance and cost competitiveness promote large penetration of wind energy into the electrical power systems. The annual wind power development indicates that among the years 2000 to 2006 , there was a substantial growth in wind power, while the expected use of wind power double among the years 2006 to 2011 [1].

In the small wind energy domain, the existing knowledge of a grid connected PMG-based wind turbine system design and performance is quite rich. To interface the PMG-based system with grid requires a Power Conditioning System (PCS) to ensure variable-speed operation and to maximize the annual energy capture. Between the various topologies of the PCS, an intermediate DC/DC converter topology is favoured due to the ease in control complexity, higher conversion efficiency and cost competitiveness compared to the cycloconverter or back-to-back PWM inverters topology. The intermediate DC/DC converter topology employs a rectifier, a boost converter prior to a grid connected inverter. However, irrespective of the PCS topology used for a variable-speed operation, the maximization of the output energy

\footnotetext{
*Address correspondence to this author at the Department of Electrical and Computer Engineering, University of New Brunswick, Fredericton, NB, Canada E3B 5A3, Canada; Tel:(506) 999-2357; Fax: (506) 453-3589;

E-mail: arifujj@unb.ca, sumon326@yahoo.com
}

is greatly dominated by an appropriate control strategy. The control strategy should also ensure that the mechanical or electrical stress on the system components is minimal and within rated condition. To achieve these criteria, active stall, passive stall, or pitch control can be applied [2], however, dependence on the airfoil design and system complexity are the major obstacle of such controls. In contrast, furling control is promising and has received a tremendous concentration in the small wind turbine area [3, 4]. Nevertheless, to track the maximum power as well as maintain the flow of maximum power to the grid is also an essence of an entire control strategy for a feasible variable speed operation. Optimum tip-speed-ratio control [5], hill climbing control [6], perturbation and observation [7] are common to track the maximum power, while a constant DC link voltage ensures the maximum power flow to the grid [8]. However, in order to achieve such control objectives, multiple controller and several system variables are required. These multiple controllers and sensing system variables pose grim constraint on the large penetration of small wind power due to the increment of system complexity as well as the cost of installation. Moreover, as far as the simulation is concerned, tuning of multiple controller parameters necessitate intense trial and error. Based on the above discussions, this paper proposes a suitable control strategy that ensure the aerodynamic power control, maximum power point control and the maximum power flow control to the grid from a grid connected PMGbased small wind turbine system. The aerodynamic power is controlled by adoption of the furling control, while the maximum power is controlled by operating the Wind Turbine (WT) at an optimum speed with the variation in wind speed. In order to ensure the maximum power flow to the 
grid, a controller is proposed that derived from the maximum power point controller thus eliminates the obligation of any additional controller or system variables. The control strategy is applied on the intermediate DC/DC converter based PCS topology. This paper is organized as follows: The first section is a short overview of the past literature and basic intention of the paper. In the second and third section the modeling of small wind turbine system components and controller realization is presented respectively. The fourth section contains the simulation results and discussion of the same. Finally, the findings of the investigations are highlighted in the conclusion.

\section{SYSTEM DESCRIPTION AND MODELING}

A variable-speed wind turbine when connected to the grid should be controlled to extract and flow the maximum power to the grid. Dynamic modeling and simulation is required to determine the effectiveness of the control strategy before deployment of a system. The wind turbine used in this work is considered as a direct drive system. The generator is connected to the grid through a rectifier, boost converter and an inverter. The torque produced by the wind turbine reflects to the PMG and low voltage produced by the PMG is rectified and boosted using a boost converter in order to maintain an adequate DC link voltage for proper working of the inverter. For this work, the maximum power point controller control the optimum speed of the generator for maximum power production of the wind turbine and the maximum power flow controller ensures the proper flow of power to the grid by maintaining an adequate DC link voltage. A complete schematic of the system is shown in Fig. 1 and the modeling is described afterwards.

A wind turbine can be characterized by the nondimensional curve of power coefficient, $C_{p}$ as a function of Tip Speed Ratio (TSR), $\lambda$, where, $\lambda$ is given in terms of rotor speed, $\omega_{s}(\mathrm{rad} / \mathrm{s})$, wind speed, $w(\mathrm{~m} / \mathrm{s})$, and rotor radius, $R_{w}$ (m) as

$\lambda=\frac{R_{w} \omega_{s}}{w}$

The relationship between $C_{p}$ and $\lambda$ can be approximated by a quartic equation. In this research, the curve is obtained from the literature [9]. A model for $C_{p}$ as a function of $\lambda$ is calculated and the curve generated by the approximate model and the actual data are presented in Fig. 2a. Statistical analysis shows that the $R^{2}$ value of the model is $99.8 \%$ and the p-

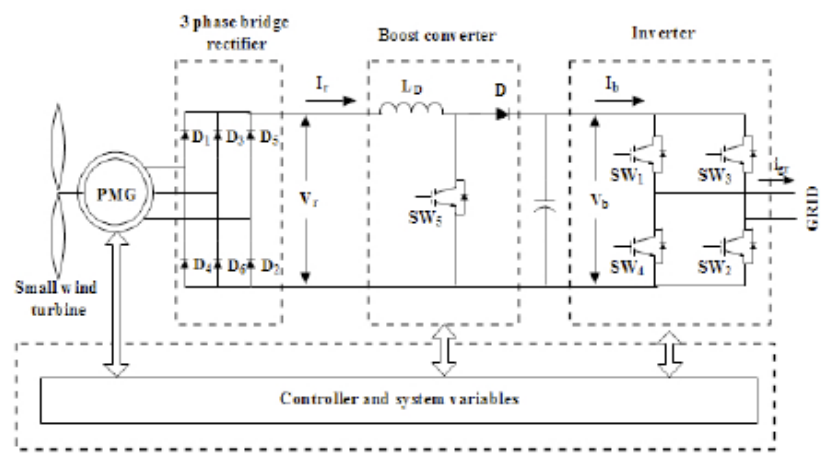

Fig. (1). A grid connected PMG-based small wind turbine system. value from the chi-square goodness-of-fit test is less than 0.0001 , which shows that the predicted model for $C_{p}$ with the fitted coefficients is acceptable. The resulting equation is found to be

$$
C_{p}(\lambda)=0.00044 \lambda^{4}-0.012 \lambda^{3}+0.097 \lambda^{2}-0.2 \lambda+0.11
$$

The curve between wind speed and furling angle is derived from published data [10]. An approximate model is used to determine the relation between wind speeds and furling angle. It is found that a fifth order model is sufficient to represent the relationship. The $R^{2}$ value and the p-value from the chi-square goodness-of-fit test of the expected model are found to be $98.19 \%$ and less than 0.0001 respectively, thus validating the modeling approach.

The modeling equation for the wind turbine is determined as

$\theta=0.00019282 w^{5}-.011317 w^{4}+0.21115 w^{3}-$

$1.179 w^{2}+1.4072 w+3.1628$

where $\theta$ is the furling angle in degree. The actual data and approximated model curve are represented in Fig. $2 \mathbf{b}$.

The furling action should be achieved within a reasonable time span and it is assumed that the furling action would take 10 seconds to attain the wind turbine rotor in its stable state. The second order dynamics for this furling action is considered as
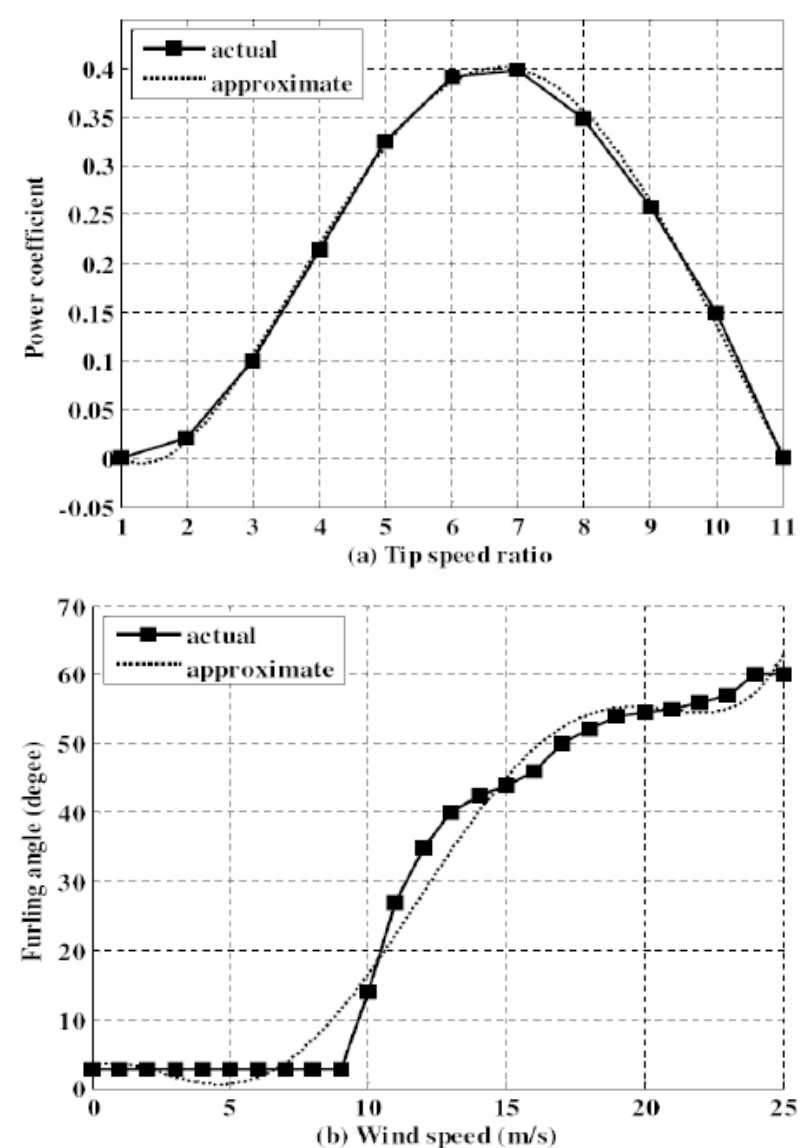

Fig. (2). a) Power coefficient as a function of TSR, b) Furling angle vs. wind speed. 


$$
H(s)=\frac{1}{1.3 s^{2}+.96 s+1}
$$

The output power of the wind turbine can be expressed as

$$
P_{\text {aero }}=0.5 \rho A C_{p}(\lambda) w^{3}
$$

where, $\rho$ is the air density $\left(\mathrm{kg} \cdot \mathrm{m}^{-3}\right)$ and $A$ is the rotor rotational area, i.e., $\pi R_{w}{ }^{2}$.

When the wind speed increases, small wind turbines yaw to an angle $\theta$ along its horizontal axis because of the furling action. The effective wind velocity at the rotor plane in that case will be $w \cos \theta[11]$. Incorporating the furling action, the theoretical power of the wind turbine can be written from (5) as

$$
P_{w}=0.5 \rho A C_{p}(\lambda)(w \cos \theta)^{3}
$$

Equation (6) represents the power for varying wind speed of the wind turbine rotor without accounting for maximum power production.

The torque produced by the wind turbine is given by

$$
T_{w}=\frac{P_{w}}{\omega_{s}}
$$

The wind turbine incorporates a furling mechanism based on a PMG, which is a $1.8 \mathrm{~kW}, 4$ pole and a rated speed of $1800 \mathrm{rpm}$. The output voltage of the generator varies with the variation of wind speed. Hence the 3-phase output of the $\mathrm{PMG}$ is rectified with an uncontrolled full wave diode bridge rectifier and fed to (DC/DC) boost converter. For an unloded and lossless PMG, the line to line voltage is given as:

$V_{g}=K_{v} \omega_{g} \sin \omega_{g} t$

where $K_{v}$ is the voltage constant and $\omega_{g}$ is the rotor angular velocity of the generator $(\mathrm{rad} / \mathrm{s})$.

The rotational speed and the torque can be related as

$T_{w}=J \frac{d \omega_{s}}{d t}+B \omega_{s}-T_{e}$

where $T_{e}$ is the electromagnetic torque of the generator, $J$ is the generator-rotor inertia and $B$ is the friction constant of the generator.

The mechanical angular velocity of the rotor $\omega_{s}$ is related to the generator electrical frequency as

$$
\omega_{g}=\omega_{s} \frac{n_{p}}{2}
$$

where $n_{p}$ is the number of poles of the PMG.

Neglecting commutation delays and diode resistive drops in an uncontrolled rectifier, the output of the rectifier is given by

$$
V_{r}=\frac{3 \sqrt{2}}{\pi} V_{g}-2 V_{f}
$$

where $V_{f}$ is the forward voltage drop of a diode. The power output at the rectifier terminal is given by
$P_{r}=V_{r} I_{r}$

where $I_{r}$ is the output current of the rectifier coupled generator feeding the load (including power conditioning systems)

The boost converter is modeled to yield a constant voltage, $V_{b}$ at the output by varying the duty cycle, $\mathrm{d}$ in response to variations in $V_{r}$. The output voltage and current, $I_{b}$ of the boost converter is presented in (13) and (14) respectively.

$$
\begin{aligned}
& V_{b}=\frac{V_{r}}{1-d} \\
& I_{b}=I_{r}(1-d)
\end{aligned}
$$

The inverter is modeled by assuming the basic principle of the sinusoidal Pulse Width Modulation (PWM) operation. The characteristic of the output is assumed to be unipolar in nature, i.e, fluctuates between $+V_{b}, 0,-V_{b}$. The unipolar modulation has the advantage of effectively doubles the switching frequency, while the actual switching frequency remains unchanged. As a consequence, the lowest harmonic in the output voltage harmonic spectrum is twice the switching frequency.

\section{CONTROLLER REALIZATION}

\section{A. Maximum Power Point Controller (MPPC)}

The method of maximum power point tracking characteristic of the wind turbine is explained using Fig. 3 where the power versus speed characteristic to five wind speed velocities are shown. It is evident that for a certain wind speed, the power output from the wind turbine increases as the turbine is allowed to increase the rotational speed. This increase continues up to a certain speed, beyond which the output starts to decrease. It is evident then that for each wind speed, there is an optimum rotational speed which provides the maximum production of the available power in the wind stream. The curve joining these points is the maximum power locus and is the objective of the paper to operate the system along it. This is achievable once the system maintains an optimum TSR, $\lambda, O P T$ and consequently results an optimum power coefficient, $C_{p, O P T}(\lambda)$ thus the maximum power point can be expressed from (5) as

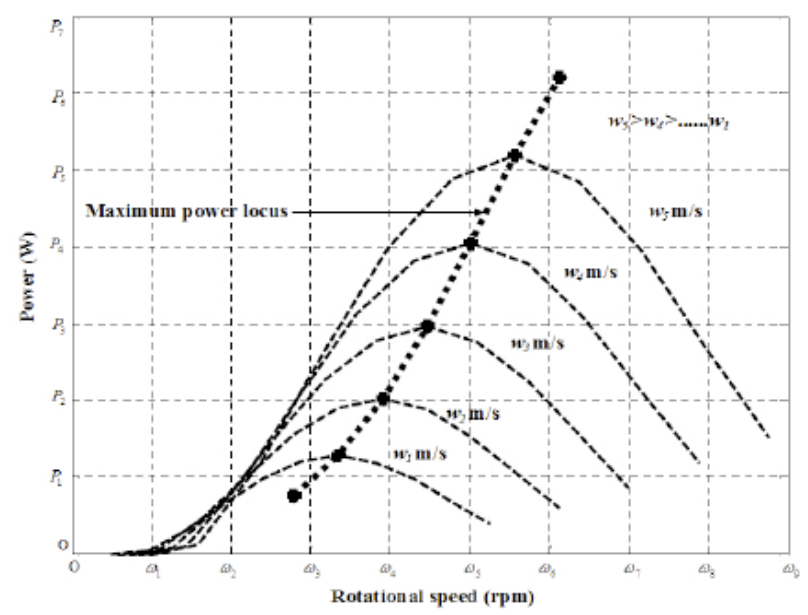

Fig. (3). Power vs. speed characteristic of a wind turbine. 


$$
P_{m}=0.5 \rho A C_{p, O P T}(\lambda)(w \cos \theta)^{3}
$$

For a variable speed wind turbine, this reflects that as the wind speed changes the rotor speed should be adjusted proportionally. Typically, the wind speed is not a satisfactory controllable parameter due to the stochastic nature and time delay in measurement. However, a simple manipulation of (15) is able to provide the rotor speed information and the reference rotational speed, $\omega_{s}{ }^{*}$ is then calculated as

$\omega_{s}^{*}=\sqrt[3]{\frac{P_{m}}{K_{O P T}}}$

where $K_{O P T}=0.5 \rho A C_{p, O P T}\left(\frac{R_{w}}{\lambda_{O P T}}\right)$

Furthermore, regarding the system and control approach described above, the controller receives the reference speed of the wind turbine and compares with the actual speed of the generator, and the controller output is given by

$\omega_{s}^{*}=K_{p}\left(\omega_{s}^{*}-\omega_{s}\right)+K_{i} \int\left(\omega_{s}^{*}-\omega_{s}\right) d t$ Fig. 4.

A basic diagram of the MPPC control loop is shown in

\section{B. Maximum Power Flow Controller (MPFC)}

The next control objective is to ensure the DC link voltage to a constant value in order to flow maximum power to the grid. An adequate dc link voltage is a major precondition to achieve a desirable output current from the grid connected inverter. Failing to do so results improper function of the inverter regardless the method employs to control the inverter. Furthermore, current dip of the inverter increase with a decrease in dc link voltage and increases the harmonics content of the current. In addition, power will start oscillating between the dc link and grid and the wind turbine system will not extract any energy even it is in operation. As a result, this paper proposes a simple yet effective maximum power flow controller to achieve this objective. The output voltage of the boost converter should have the proper coordination with the $60 \mathrm{~Hz}, 208$ volt grid. The basic principle of the proposed maximum power flow controller is described as follows:

Assuming the grid voltage is

$v_{g r}(t)=v_{g r, m} \sin \omega t$

where $v_{g r, m}$ is the peak amplitude of the grid voltage. Since the output current of the inverter ensures a sinusoidal waveform and in phase with the grid voltage, the output current to

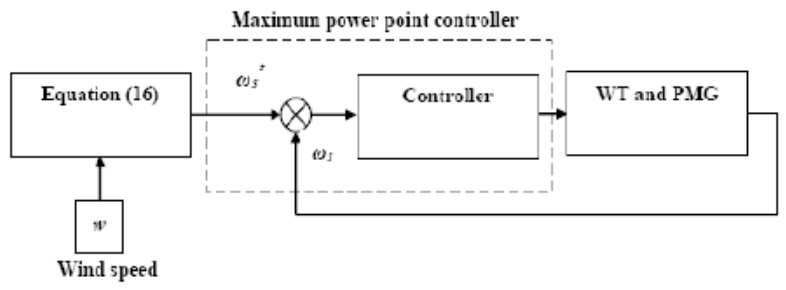

Fig. (4). Structure of the maximum power point controller. the grid can be expressed as

$i_{g r}(t)=i_{g r, m} \sin \omega t$

where $i_{g r, m}$ is the peak amplitude of the grid current. Thus the output real power flowing to the grid can be expressed as

$p(t)=v_{g r}(t) i_{g r}(t)=V_{g r} I_{g r}$

where $V_{g r}$ and $I_{g r}$ is the RMS value of the grid voltage and current.

The output power of the boost converter can be expressed as

$P_{b}=V_{b} I_{b}$

Equating (20) and (21) results in

$I_{b}=\frac{V_{g r}}{V_{b}} I_{g r}=K_{G} I_{g r}$

It is evident then controlling the boost converter current to an optimum value ensure the maximum current flow into the grid, while boost converter output voltage is at a predetermined constant value in coordination with the constant grid voltage. Recall from (13) and (14), an appropriate voltage and current at the boost converter output can be achieved by varying the duty cycle of the switch.

Considering this approach, a relation between the optimum duty cycle and optimum rotational speed of the generator or wind turbine can be established using (8) to (11) and expressed by (23) and a basic diagram of the MPFC control loop is presented in Fig. 5.

$d^{*}=1-\frac{\frac{3 \sqrt{2} n_{p}}{2 \pi} K_{v} \omega_{s}^{*}-2 V_{f}}{V_{b}}$

Equation (23) presents the duty cycle required for maximum power flow to the grid. The advantage of the proposed controller is the dependence on only one parameter, i.e., rotational speed thus greatly reduces implementation cost of any extra controller or sensing circuitry as considered an essence for controlling the boost converter output voltage or current.

\section{SIMULATION RESULTS}

The system described above was simulated using MatlabSimulinkTM environment. A pseudorandom wind speed profile was built; thus the input to the systems was a series of steps, each one of same duration of 10 seconds. Although real wind does not occur with such abrupt slopes, a series of

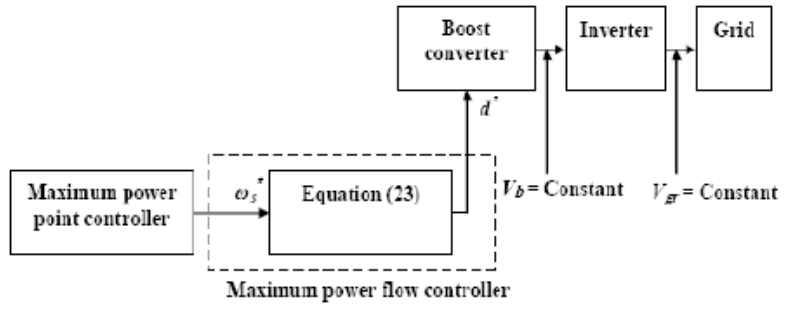

Fig. (5). Structure of the maximum power flow controller. 
steps is a standard testing signal which permits a clear interpretation of the system behavior. Fig. 6 shows the considered power versus speed characteristic of the wind turbine for a wind speed variation of $6.1 \mathrm{~m} / \mathrm{s}, 6.7 \mathrm{~m} / \mathrm{s}, 7.5 \mathrm{~m} / \mathrm{s}, 8.1 \mathrm{~m} / \mathrm{s}$ and $8.5 \mathrm{~m} / \mathrm{s}$. It can be found that for each wind speed (Fig. 7a), Fig. 7b shows that the expected furling dynamics of the wind turbine rotor reached a stable state (within 10 seconds) and the furling angle for each wind speed corresponds with the value obtained in (3), for example, a furling angle of 9.10 is found for the wind speed of $8.5 \mathrm{~m} / \mathrm{s}$ and the conclusions remain same for the other wind speeds as well. The corresponding rotor speed in rpm is shown in Fig. 7c. It is shown that after each step, the MPPC settles the rotational speed of the wind turbine to an optimum value and corresponds well with the value obtained from the power versus speed characteristic curve of the wind turbine in consideration. The observable fact thus ensures the variable-speed operation and most importantly, maximum power production by the wind turbine. The controller values were calculated simple Ziegler-Nichols (ZN) method. The suitable controller parameter was found as; $\mathrm{Kp}=2.31$ and $\mathrm{K} \mathrm{i}=9.5$. The power coefficient corresponding with the wind speeds is shown in Fig. 7d and it is notable that the value remains to a maximum of 0.42 as expected from (2). The simulation results of the PMG under the sway of the MPFC controller is presented afterwards. The PMG output voltage (Fig. 8a) and current

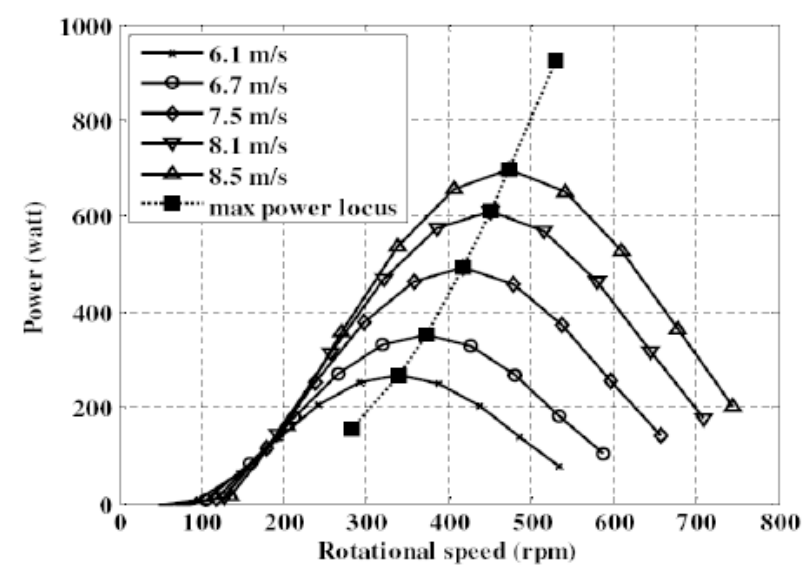

Fig. (6). Simulated power vs. speed characteristic of the wind turbine.
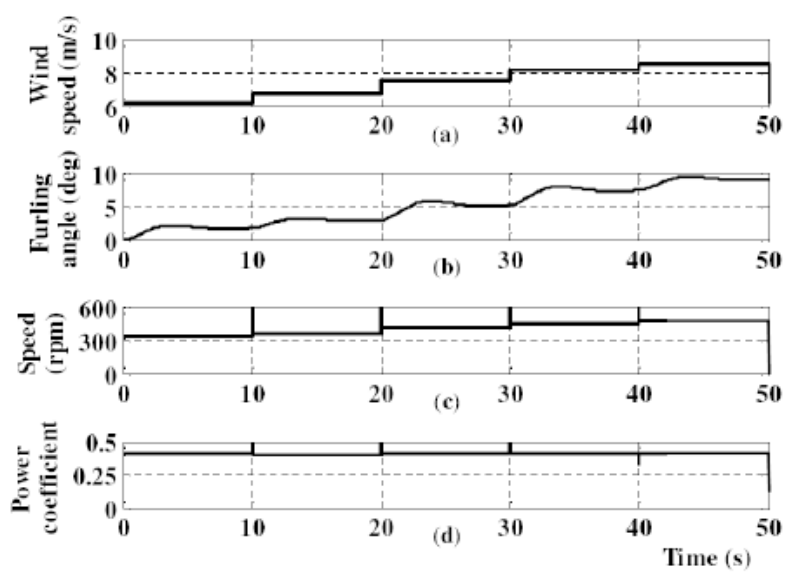

Fig. (7). The time variation of a) Wind speed, b) Furling angle, c) Rotational speed, d) Power coefficient.
(Fig. 8b) increases with an increase in wind speed and the corresponding power (Fig. 8c) also shows the similar nature. A closer glance of the PMG output voltage and current is presented in Fig. 9a and Fig. 9b respectively. The nature of the output voltage and current remains sinusoidal as expected thus validates the modeling approach of the generator. Afterwards the rectifier voltage and current is presented in Fig. 10a and Fig. 10b respectively. It is observable that as soon as the wind speed starts to increase, the rectifier voltage and current increases to cope with the higher maximum power from the wind turbine. It is clear from Fig. 11a that the proposed MPFC effectively controls the boost converter output voltage to be around the reference value $\left(\sqrt{ } 2 \times V_{g r}\right)$. In addition, the current is maintained to the value as required for the maximum power (Fig. 11b). The analogous duty cycle variation is also presented in Fig. 11c. It is well understood that a constant DC link voltage in proper coordination with the grid voltage ensure the correct amount of power flow between the inverter input and grid output. Moreover, the constant DC voltage should also ensure an undistorted current injection to the grid. As a result, the variation and a closer observation of grid current is presented in Fig. 12a and Fig. 12b respectively and corresponding grid output power by Fig. 12c. In order to cope with the higher power demand with increasing wind speed, an increase in current is required as the voltage of the grid remain constant and is found from the simulation result for the current. Furthermore, it is observable the current maintain the proper sinusoidal profile as expected from the PWM inverter. The objective to transfer maximum power to the grid is no longer questionable as the power corresponds well with the maximum power with respective wind speeds.

\section{CONCLUSION}

Modeling and simulation results of a grid connected PMG-based small wind turbine system is analyzed and presented in this paper. A control strategy is designed which effectively reduces the dependence on system variables and lowered the system complexity. The obstacle at high wind speed situation is addressed using a furling control, while the maximum power is controlled using a maximum power point controller. It has been found that the proposed maximum power point controller is able to maintain the maximum power extraction from the wind turbine system. In addition,
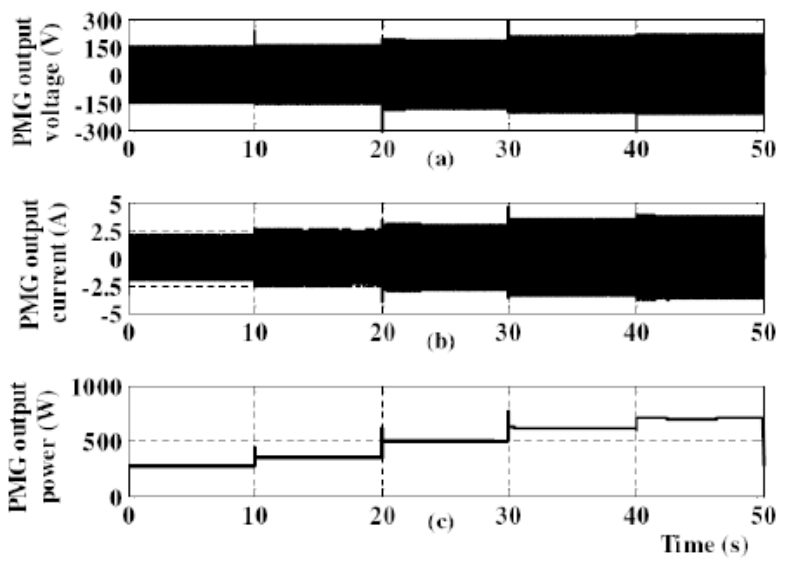

Fig. (8). The time variation of a) PMG output voltage, b) PMG output current, c) PMG output power. 


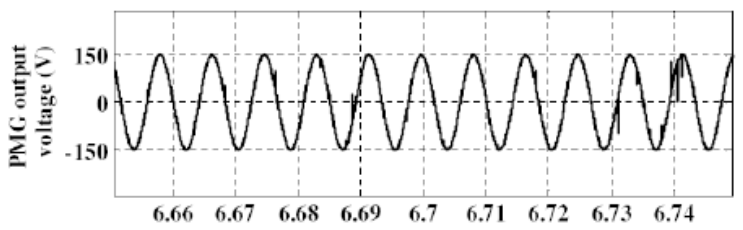

(a)

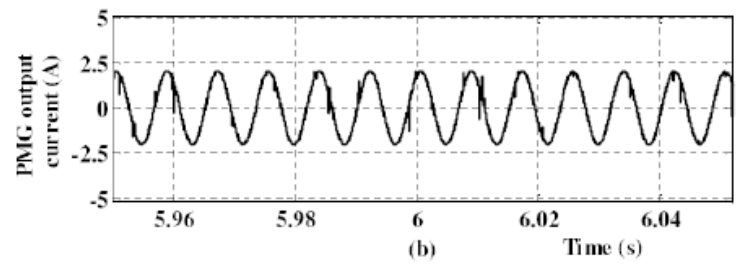

Fig. (9). The time variation of a) PMG output voltage, b) PMG output current.
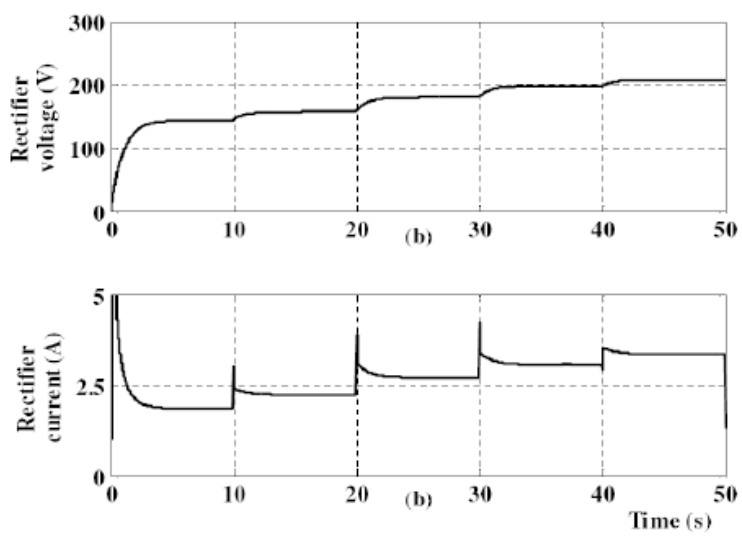

Fig. (10). The time variation of a) Rectifier output voltage, b) Rectifier output current.

the proposed maximum power flow controller is able to maintain an adequate dc link voltage thus ensured the proper sinusoidal current injection to the grid. The results of the simulation are shown to prove the conclusions and to verify the effectiveness of the control strategy. The proposed control strategy has a stable operation for different wind speeds. Testing and experimental results on the simulated system will be published in future publications.

\section{REFERENCES}

[1] http://www.btm.dk/(accessed March 30, 2010)

[2] Hoffmann, R.; Mutschler, P. The Influence of Control Strategies on the Energy Capture of Wind Turbines. In: Industry Applications Conference, Rome, Italy, October 8-12, 2000.

[3] Marques, J.; Pinheiro, H. Grundling, H.; Pinheiro, J.; Hey, H. A Survey on Variable-speed Wind Turbine System. In: Brazilian Power Electronics Conference, Fortaleza, Brazil, September 21-24, 2003.

[4] Arifujjaman, Md.; Iqbal, M.T.; Quaicoe, J. E. Performance comparison of grid connected small wind energy conversion systems. Wind Engineering, 2009, 33,1-18.
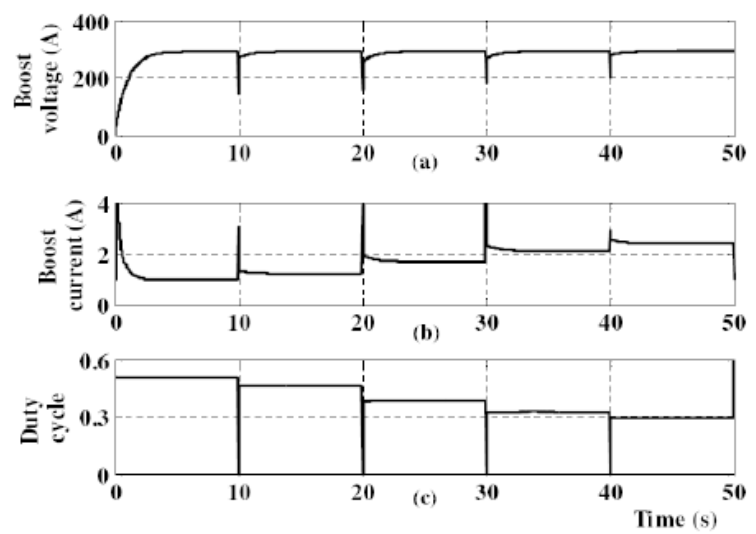

Fig. (11). The time variation of a) Boost converter output voltage, b) Boost converter output current, c) Duty cycle of the boost converter.
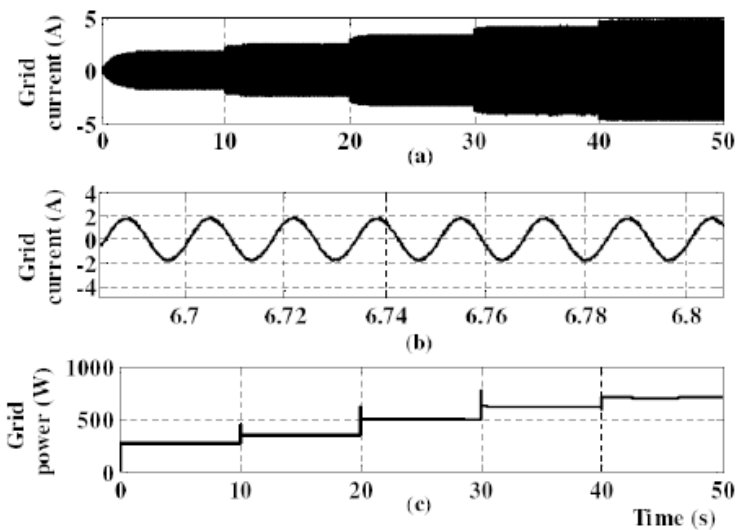

Fig. (12). The time variation of a) Grid output current, b) Grid output current, c) Grid output power.

[5] Welfonder, E.; Neifer, R.; Spanner, M. Development and experimental identification of dynamic models for wind turbines. Control Engineering Practice, 1997, 5, 67-73.

[6] Iqbal., M.T. Modeling and Simulation of a Small Wind Turbine, In: IEEE Newfoundland Electrical and Computer Engineering Conference, St. John's, Canada, November 2003.

[7] Datta, R.; Ranganathan, V.T. A method of tracking the peak power points for a variable speed wind energy conversion system. IEEE Transaction on Energy Conversion, 2003, 18, 163-168

[8] Huang, H.; Chang, L. Energy-flow Direction Control of GridConnected IGBT Inverters for Wind Energy Extraction. In: IEEE Canadian Conference on Electrical and Computer Engineering, Halifax, Canada, May 7-10, 2000.

[9] Muljadi, E.; Forsyuth, T; Butterfield, C.P. Soft-stall Control Versus Furling Control for Small Wind Turbine Power Regulation, pp. 12; NREL Report No. CP-500-25100.

[10] Corbus, D.; Prascher, D. Analysis and Comparison of Test Results from the Small Wind Research Turbine Test Project, In AIAA Aerospace Sciences Meeting and Exhibit, Reno, Nevada, January 10-13, 2005.

[11] Bialasiewicz, J.T. Furling control for small wind turbine power regulation. In: Industrial Electronics, Rio de Janeiro, Brasil, June 9-12, 2003.

(C) Md. Arifujjaman; Licensee Bentham Open.

This is an open access article licensed under the terms of the Creative Commons Attribution Non-Commercial License (http://creativecommons.org/licenses/by-nc/3.0/) which permits unrestricted, non-commercial use, distribution and reproduction in any medium, provided the work is properly cited. 